\title{
THE PROBLEMATIC ISSUES OF INFLICTING PENALTY FOR EXCEEDING THE PRESCRIBED AVERAGE SPEED LIMITS
}

\author{
Alexander V. Sarychev \\ Belgorod Law Institute of the Ministry of Internal Affairs of Russia named after I.D. Putilin, \\ Belgorod, Russian Federation \\ Ivan N. Arkhiptsev \\ Belgorod Law Institute of the Ministry of Internal Affairs of Russia named after I.D. Putilin, \\ Belgorod, Russian Federation \\ Ekaterina V. Ryzhkova \\ Belgorod Law Institute of the Ministry of Internal Affairs of Russia named after I.D. Putilin, \\ Belgorod, Russian Federation
}

Introduction: currently, in the Russian Federation, an urgent problem is exceeding the speed limit by drivers of vehicles, for which they are held liable. This offense is regulated by Article 12.9 of the Code of Administrative Offenses of the Russian Federation. The purpose of the research is to study the problem of exceeding the average traveling speed limits and identify the ways to solve it. Methods: the methodological framework for the research is based on the general scientific methods of cognition. In order to ensure the objectivity of the research, the problem under study is revealed as a phenomenon using a systematic approach, which allows us to reveal its mechanism in such a way that the theoretical provisions are used with the maximum efficiency in the practical activities. Results: the authors propose to specify Article 12.9 of the Code of Administrative Offences and improve the devices that allow measuring the average traveling speed, or even stop the practice of using this method. Conclusions: the study showed the imperfection of the current legislation and the problem of imposing penalties for exceeding the prescribed average speed. The necessity of changing the current administrative legislation of the Russian Federation is justified.

Key words: average fines for speed, sentencing, fines for average speed, special technical speed measurement devices, automobile offenses.

Citation. Sarychev A.V., Arkhiptsev I.N., Ryzhkova E.V. The Problematic Issues of Inflicting Penalty for Exceeding the Prescribed Average Speed Limits. Legal Concept, 2020, vol. 19, no. 3, pp. 67-72. (in Russian). DOI: https://doi.org/10.15688/lc.jvolsu.2020.3.9

УДК 342.9

Дата поступления статьи: 14.06.2020

ББК 67.401

Дата принятия статьи: 10.07.2020 \section{ЗА ПРЕВЫШЕНИЕ УСТАНОВЛЕННОЙ СРЕДНЕЙ СКОРОСТИ ДВИЖЕНИЯ \\ ПРОБЛЕМНЫЕ ВОПРОСЫ НАЗНАЧЕНИЯ НАКАЗАНИЯ}

\section{Александр Викторович Сарычев}

Белгородский юридический институт МВД России им. И.Д. Путилина, г. Белгород, Российская Федерация

\section{Иван Николаевич Архипцев}

Белгородский юридический институт МВД России им. И.Д. Путилина, г. Белгород, Российская Федерация

\section{Екатерина Владимировна Рыжкова}

Белгородский юридический институт МВД России им. И.Д. Путилина, г. Белгород, Российская Федерация 
Введение: в настоящее время в Российской Федерации актуальной проблемой является превышение установленной скорости движения водителей транспортных средств, за которое привлекают к ответственности. Данное правонарушение урегулировано ст. 12.9 Кодекса РФ об административных правонарушениях. Цель исследования - изучить проблему нарушения средней скорости движения и выявить способы ее решения. Методы исследования. Методологическую основу данной работы составляют общенаучные методы познания. С целью обеспечения объективности исследования анализируемая проблема раскрывается нами как явление с использованием системного подхода, что позволяет раскрыть его механизм таким образом, чтобы теоретические положения с максимальной эффективностью использовались в практической деятельности. Результаты исследования. Авторами предлагается законодательно конкретизировать ст. 12.9 Кодекса РФ об административных правонарушениях и усовершенствовать приборы, позволяющие измерять среднюю скорость движения, или же вообще прекратить практику применения данного метода. Выводы. Проведенное исследование показало несовершенство действующего законодательства и проблемы назначения наказания за превышение установленной средней скорости движения. Обоснована необходимость изменения действующего административного законодательства Российской Федерации.

Ключевые слова: средняя скорость, назначение наказания, штрафы за среднюю скорость, специальные технические устройства измерения скорости, автомобильные правонарушения.

Цитирование. Сарычев А. В., Архипцев И. Н., Рыжкова Е. В. Проблемные вопросы назначения наказания за превышение установленной средней скорости движения // Legal Concept = Правовая парадигма. 2020. - T. 19, № 3. -C. 67-72. - DOI: https://doi.org/10.15688/lc.jvolsu.2020.3.9

\section{Введение}

В настоящее время ведется много споров по поводу привлечения к ответственности на основании превышения средней скорости [7]. На данный момент в Российской Федерации нет закона, который бы прямо указывал на запрет применения данного метода, но из-за наличия значительных недостатков есть много его противников [8]. В Государственной думе РФ рассматривается законопроект о внесении изменений в административное законодательство в области превышения скоростного режима. Для объективной оценки необходимо всесторонне изучить достоинства и недостатки такой системы и практики ее применения.

\section{Штрафы за превышение средней скорости}

Вначале следует указать, что как такового понятия средней скорости в действующем законодательстве не существует, хотя в комментарии к ст. 12.9 Кодекса Российской Федерации об административных правонарушениях [4] указано, что факт превышения установленной скорости должен быть во всех случаях установлен при помощи специального технического устройства, имеющегося у сотрудников ГИБДД. К специальным техническим средствам относятся имеющие функ- ции фото- и киносъемки, видеозаписи, работающие в автоматическом режиме устройства. В законе не определены конкретные способы, которые устанавливают превышение скоростного режима. Свое несогласие с данным методом фиксации превышения скорости высказывают члены партии ЛДПР, много раз ими подавались инициатива и рекомендация об установке запрета на такой штраф [2]. Те, кто придерживаются положительной позиции по поводу данной нормы, обосновывают это положением главы 10 ПДД, из которой следует, что водитель обязан соблюдать скоростные ограничения как в конкретный момент, так и «на протяжении всего периода вождения».

Актуальность данной проблемы состоит также в том, что в последнее время большое количество водителей привлекается к ответственности в связи с тем, что комплексы, измеряющие среднюю скорость, не излучают электромагнитных волн и поэтому антирадары не реагируют и не предупреждают водителя о наличии такого устройства. С одной стороны, очевидна эффективность таких установок, так как из-за невозможности выявить места дислокации таких камер водитель будет соблюдать скоростной режим на протяжении всего пути. Как отметил начальник ЦАФАП ГИБДД Самарской области Алексей Платов: «За этот период комплексами выявлено более 190 тысяч правонарушений. С момента установки комплексов не зарегистрировано на этих 
участках дорог ни одного ДТП» [6]. Есть результаты исследований и в других регионах России [1, с. 178-181]. Таким образом, положительное влияние данных комплексов очевидно. С другой стороны, несмотря на это, существует большое количество нюансов и недоработок, которые являются минусами и вызывают противоречия.

Прежде всего, следует сказать о принципе действия таких камер. Для измерения средней скорости используются комплексы «Автодория», которые работают с помощью системы ГЛОНАСС. Комплекс фиксирует скоростной режим на участках протяженностью от 500 до 10000 метров. На протяжении данного промежутка дороги на определенном расстоянии друг от друга устанавливаются регистраторы. Пара рядом расположенных таких устройств образуют зону контроля. Оба устройства регистрируют номерной знак автомобиля, определяют его месторасположение и время. После данные «маркируются» электронно-цифровой подписью и передаются в Единый вычислительный центр (далее ЕВЦ). ЕВЦ «Автодории», приняв данные от пары регистраторов, сравнивает номерной знак, определяет местоположение авто в начале зоны контроля и в конце, а также время, за которое машина проехала этот промежуток дороги. Путем простейших вычислительных операций центр определяет среднюю скорость движения и в случае превышения скоростного режима автоматически оформляет штрафную квитанцию.

В настоящее время поступает значительное количество предложений об отмене штрафа за превышение средней скорости. В пояснительной записке к законопроекту об отмене штрафа говорится: «Привлечение к административной ответственности на основе догадок, домыслов и расчетов недопустимо» [2]. Соответствующие изменения хотят внести и в КоАП. Так, ст. 1.7 и ст. 1.8 КоАП будут дополнены тем, что ответственность наступает только в случаях, когда правонарушение выявлено в конкретном месте и в конкретное время. Нововведения затронут и ст. 1.5 КоАП [3], она будет дополнена следующим абзацем: «Не является доказательством административного правонарушения фиксация превышения ус- тановленной скорости движения транспортного средства на участке проезжей части дороги на основании расчета средней скорости движения транспортного средства наданном участке, а также фиксация нарушения правил расположения транспортного средства на участке проезжей части дороги на основании фиксации расположения транспортного средства в начале и в конце данного участка, без фиксации правонарушения в конкретно установленном месте и в конкретно установленное время» [2]. Таким образом, это будет прямым запретом на привлечение к ответственности в связи с применением средней скорости.

Недостатки данного способа контроля водителей заключаются в следующем. Так как в КоАП РФ размер штрафа напрямую зависит от того, насколько была превышена допустимая скорость, при расчете средней скорости этого сделать невозможно, так как водитель может превысить на определенном участке дороги разрешимое значение, которое будет охватываться самым строгим наказанием, а после снизить скорость до минимума и камеры рассчитают среднее значение, которое будет ниже, чем он превысил изначально. Еще одной важной особенностью данного комплекса является расположение таких камер. Необходимо учитывать, что их нужно устанавливать только в тех местах, где нет возможности сократить путь до второй камеры, иначе водителя будут привлекать к ответственности без его вины, что противоречит принципам законодательства Российской Федерации. Что касается обжалования данных постановлений, встает вопрос о территориальной подсудности. Если лицо, которому выписан такого рода протокол, решит его обжаловать, возникнет проблема по поводу того, в какой суд обращаться. При вычислении средней скорости невозможно определить конкретное место проступка, а значит и суд, к компетенции которого будет относиться данное дело. Он нарушает право владельца транспортного средства на защиту. Данную проблему можно решить, если камеры будут устанавливаться в области одного населенного пункта, а так как они располагаются в основном на трассах, отрезок населенного пункта очень короткий 


\section{ТЕОРИЯ И ПРАКТИКА ГОСУДАРСТВЕННО-ПРАВОВОГО РАЗВИТИЯ}

и, следовательно, расстояние между камерами будет небольшое, что снизит их эффективность. Еще одной актуальной проблемой является то, что невозможно установить, кто именно находился за рулем автомобиля. Как известно, штраф за нарушение ПДД приходит на собственника. Если управлял транспортным средством не собственник, то последний должен доказывать, что во время правонарушения находился не за рулем, что затрудняет процесс производства по делу.

В связи с тем, что данное правонарушение нередко обжалуют, существует неоднозначная судебная практика. Так, если обратиться к постановлению Верховного Суда РФ от 07.10.2019 № 36-АД19-3, то можно увидеть, что в конкретном случае нарушения Б. скоростного режима суд признал привлечение к ответственности на основании превышения средней скорости незаконным. «Меры к всестороннему, полному и объективному рассмотрению дела судебными инстанциями не приняты. Такое разрешение дела не отвечает установленным статьей 24.1 Кодекса Российской Федерации об административных правонарушениях задачам производства по делам об административных правонарушениях» [5]. Аргументы, указанные в данном постановлении против привлечения к ответственности за среднюю скорость в конкретном случае, подпадают и под остальные подобные правонарушения. Следовательно, если все водители после получения такого штрафа будут обращаться в суд с целью его обжалования и ссылаться в своей позиции на данное постановление Верховного Суда, они будут освобождены от ответственности. Таким образом, исследуемый метод регулирования скоростного режима будет неэффективным, так как привлекаться будут только лица, которые не обладают достаточными знаниями по этому вопросу и не будут обращаться в суд с целью обжалования. Следовательно, это говорит о том, что законодательство, регулирующее это правонарушение, недостаточно хорошо разработано и что для привлечения к ответственности необходимо рассмотреть все недостатки указанного метода, которых на сегодняшний день большое количество.

\section{Вывод}

Таким образом, конфликт остается неразрешенным в связи с тем, что новый метод определения виновности не закреплен в законах, хотя при этом весьма логичен. В данном основании привлечения к ответственности есть много неточностей и спорных моментов, но оно является эффективным методом борьбы с нарушением скоростного режима. С учетом вышесказанного можно сделать вывод о том, что необходимо конкретизировать данную норму и усовершенствовать приборы, позволяющие измерять среднюю скорость движения или же прекратить вообще практику применения данного метода. Последнее слово в этом вопросе за отечественным законодателем.

\section{СПИСОК ЛИТЕРАТУРЫ}

1. Даутов, Р. А. Результаты испытаний систем фотовидеофиксации нарушений ПДД, выявленных методом определения средней скорости движения, в условиях городского движения в г. Казани / Р. А. Даутов, Л. Б. Шигин // Современные проблемы безопасности жизнедеятельности: интеллектуальные транспортные системы : материалы IV Междунар. науч.-практ. конф. (г. Казань, 25-26 февр. 2016 г.). Казань : Научный центр безопасности жизнедеятельности, 2016. - С. 178-181.

2. Законопроект № 494136-7 «О внесении изменений в Кодекс Российской Федерации об административных правонарушениях в части уточнения условий привлечения к административной ответственности» (в части исключения из доказательств административного правонарушения установление средней скорости движения транспортного средства на отдельном участке дороги). - Электрон. текстовые дан. - Режим доступа: https://sozd.duma.gov.ru/ bill/494136-7. - Загл. с экрана.

3. Кодекс Российской Федерации об административных правонарушениях от 30.12.2001 № 195Ф3 (ред. от 24.04.2020). Статья 1.5. Презумпция невиновности // Собрание законодательства РФ. 2002. - 7 янв. (№ 1, ч. 1). - Ст. 1.

4. Кодекс Российской Федерации об административных правонарушениях от 30.12.2001 № 195Ф3 (ред. от 24.04.2020). Ст. 12.9. Превышение установленной скорости движения // Собрание законодательства РФ. - 2002. - 7 янв. (№ 1, ч. 1). - Ст. 1.

5. Постановление Верховного Суда РФ от 07.10.2019 № 36-АД19-3. - Электрон. текстовые 
дан. - Режим доступа: https://legalacts.ru/sud/ postanovlenie-verkhovnogo-suda-rf-ot-07102019-n36-ad19-3. - Загл. с экрана.

6. ЦАФАП в области ДД ГИБДД ГУ МВД России по Самарской области. - Электрон. текстовые дан. - Режим доступа: https:/Гибдд.pф/r/63/ divisions/2270. - Загл. с экрана.

7. Штраф за среднюю скорость. - Электрон. текстовые дан. - Режим доступа: https://www.zr.ru/ content/news/917504-v-sudy-vernutsya-spory-oshtrafa/. - Загл. с экрана.

8. Штраф за среднюю скорость - законен ли и как обжаловать. - Электрон. текстовые дан. - Режим доступа: https://autotonkosti.ru/q/shtraf-zasrednyuyu-skorost-zakonen-li-i-kak-obzhalovat. Загл. с экрана.

\section{REFERENCES}

1. Dautov R.A., Shigin L.B. Rezultaty ispytaniy sistem fotovideofiksatsii narusheniy PDD, vyyavlennykh metodom opredeleniya sredney skorosti dvizheniya, v usloviyakh gorodskogo dvizheniya $\mathrm{v}$ g. Kazani [Test Results of Photo-Video Recording Systems for Traffic Violations Detected by the Method of Determining the Average Speed of Traffic in Urban Traffic in Kazan]. Sovremennye problemy bezopasnosti zhiznedeyatelnosti: intellektualnye transportnye sistemy: materialy IV Mezhdunarodnoy nauchnoprakticheskoy konferentsii (g. Kazan, 25-26 fevr. 2016 g.) [Modern Problems of Life Safety: Intelligent Transport Systems. Materials of the IV International Scientific and Practical Conference (Kazan, 2526 February 2016)]. Kazan, Nauchnyy tsentr bezopasnosti zhiznedeyatelnosti, 2016, pp. 178-181.

2. Zakonoproekt № 494136-7 «O vnesenii izmeneniy $v$ Kodeks Rossiyskoy Federatsii ob administrativnykh pravonarusheniyakh $v$ chasti utochneniy a usloviy privlecheniya $k$ administrativnoy otvetstvennosti» (v chasti isklyucheniya iz dokazatelstv administrativnogo pravonarusheniya ustanovlenie sredney skorosti dvizheniya transportnogo sredstva na otdelnom uchastke dorogi)
[Draft Law No. 494136-7 “On Amendments to the Code of the Russian Federation on Administrative Offenses in Terms of Clarifying the Conditions for Bringing to Administrative Responsibility" (In Terms of Excluding the Establishment of the Average Speed of a Vehicle on a Separate Road Section from the Evidence of an Administrative Offense)]. URL: https://sozd.duma. gov.ru/bill/494136-7.

3. Kodeks Rossiyskoy Federatsii ob administrativnykh pravonarusheniyakh ot 30.12.2001 № 195-FZ (red. ot 24.04.2020). Statia 1.5. Prezumptsiya nevinovnosti [Code of the Russian Federation About Administrative Offences from 30.12.2001 № 195-FZ (as amended on 24.04.2020). Article 1.5. Presumption of innocence]. Sobranie zakonodatelstva Rossiyskoy Federatsii [Collection of Legislation of the Russian Federation], 07.01.2002, no. 1 (part 1), art.1.

4. Kodeks Rossiyskoy Federatsii ob administrativnykh pravonarusheniyakh ot 30.12.2001 № 195-FZ (red. ot 24.04.2020). Statya 12.9. Prevyshenie ustanovlennoy skorosti dvizheniya [Code of the Russian Federation About Administrative Offences from 30.12.2001 № 195-FZ (as amended on 24.04.2020). Article 12.9. Exceeding the Set Speed]. Sobranie zakonodatelstva Rossiyskoy Federatsii [Collection of Legislation of the Russian Federation], 2002, 7 January, no. 1 (part 1), art. 1.

5. Postanovlenie Verkhovnogo Suda RF ot 07.10.2019 № 36-AD19-3 [Resolution of the Supreme Court of the Russian Federation of 07.10.2019 no. 36AD19-3]. URL: https://legalacts.ru/sud/postanovlenieverkhovnogo-suda-rf-ot-07102019-n-36-ad19-3.

6. Ts AFAPv oblasti DD GIBDD GU MVD Rossii po Samarskoy oblasti [CAFAP in the Field of DD STSI GU MVD of Russia in Samara Region]. URL: https:// гибдд.RF/r/63/divisions/2270.

7. Shtraf za srednyuyu skorost [Penalty for Average Speed]. URL: https://www.zr.ru/content/ news/917504-v-sudy-vernutsya-spory-o-shtrafa.

8. Shtraf za srednyuyu skorost - zakonen li $i$ kak obzhalovat? [Average Speed Penalty-is it Legal and How Can I Appeal]. URL: https://autotonkosti.ru/ q/shtraf-za-srednyuyu-skorost-zakonen-li-i-kakobzhalovat.

\section{Information About the Authors}

Alexander V. Sarychev, Lecturer, Department of Tactical and Special Training, Belgorod Law Institute of the Ministry of Internal Affairs of Russia named after I.D. Putilin, Gorkogo St, 71, 308024 Belgorod, Russian Federation,w0773@yandex.ru, https://orcid.org/0000-0002-2115-3191

Ivan N. Arkhiptsev, Candidate of Sciences (Jurisprudence), Associate Professor, Department of Criminal Legal Disciplines, Belgorod Law Institute of the Ministry of Internal Affairs of Russia named after I.D. Putilin, Gorkogo St, 71, 308024 Belgorod, Russian Federation, ArhiptsevIN@yandex.ru, https://orcid.org/0000-0003-2307-2712 


\section{ТЕОРИЯ И ПРАКТИКА ГОСУДАРСТВЕННО-ПРАВОВОГО РАЗВИТИЯ}

Ekaterina V. Ryzhkova, Cadet, Faculty of Transport Security, Belgorod Law Institute of the Ministry of Internal Affairs of Russia named after I.D. Putilin, Gorkogo St, 71, 308024 Belgorod, Russian Federation, ryzhkova.e3110@yandex.ru, https://orcid.org/0000-0001-7719-2088

\section{Информация об авторах}

Александр Викторович Сарычев, преподаватель кафедры тактико-специальной подготовки, Белгородский юридический институт МВД России им. И.Д. Путилина, ул. Горького, 71, 308024 г. Белгород, Российская Федерация, w0773@yandex.ru, https://orcid.org/0000-0002-2115-3191

Иван Николаевич Архипцев, кандидат юридических наук, доцент кафедры уголовно-правовых дисциплин, Белгородский юридический институт МВД России им. И.Д. Путилина, ул. Горького, 71, 308024 г. Белгород, Российская Федерация, ArhiptsevIN@yandex.ru, https://orcid.org/0000-0003-2307-2712

Екатерина Владимировна Рыжкова, курсант факультета обеспечения безопасности на транспорте, Белгородский юридический институт МВД России им. И.Д. Путилина, ул. Горького, 71, 308024 г. Белгород, Российская Федерация, ryzhkova.e3110@yandex.ru, https://orcid.org/0000-0001-7719-2088 